\title{
Influence of bacterial resistance on mortality in intensive care units: A registry study from 2000 to 2013 (IICU Study)
}

\author{
Bonnet V. ${ }^{1}$, Pasqualini L. ${ }^{1}$, Dupont H. ${ }^{2}$, Kipnis E. ${ }^{3}$, Hanouz J.-L. ${ }^{1}$, Fischer M.-O. ${ }^{1}$
}

1University Hospital Caen, Dept of Anaesthesiology \& Intensive Care, Caen, France, 2University Hospital Amiens, Dept of Anaesthesiology \& Intensive Care, Amiens, France, 3University Hospital Lille, Dept of Anaesthesiology \& Intensive Care, Lille, France

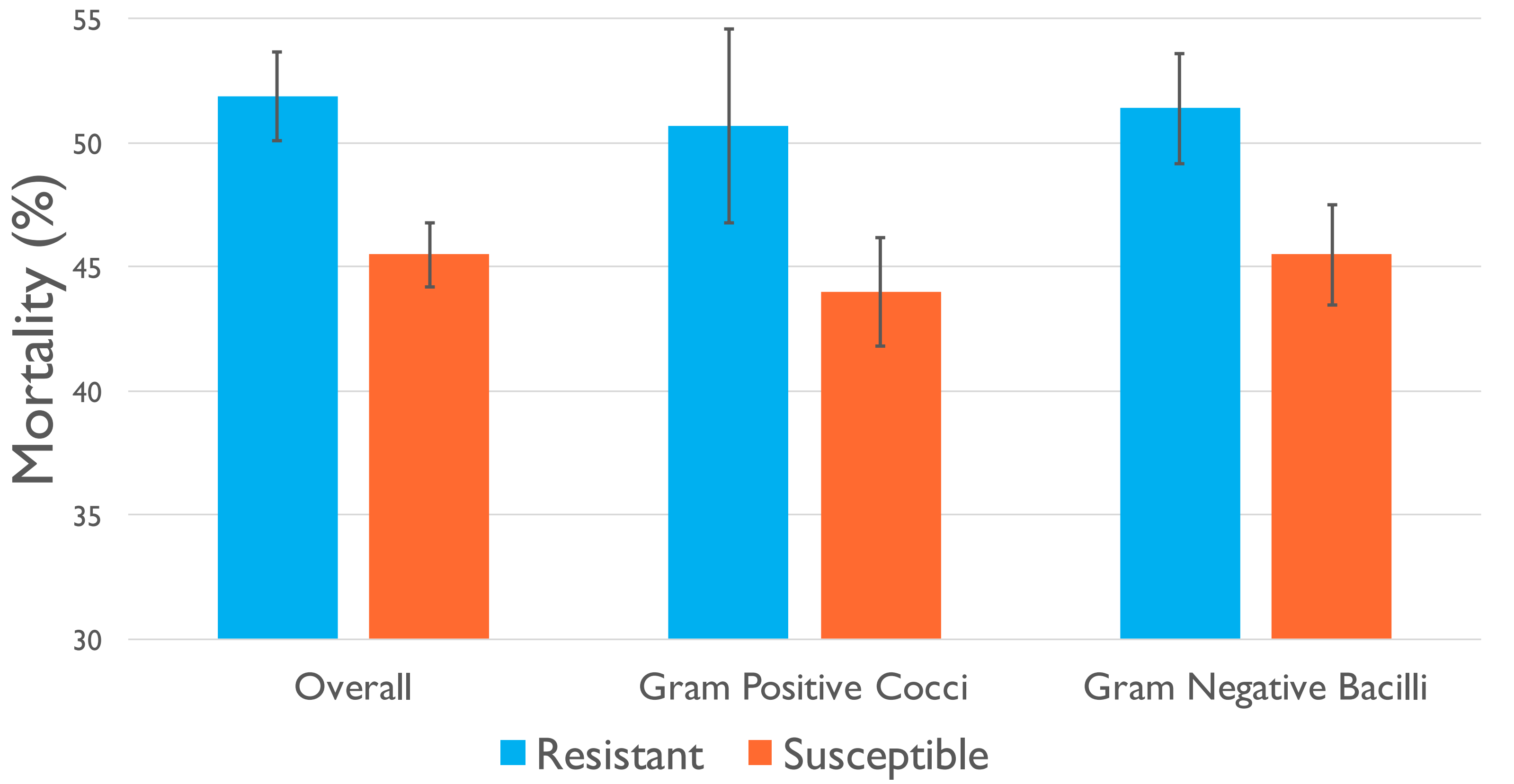

Background and Goal of Study: Bacterial resistance to antibiotics is a daily concern in intensive care units and represent a major public health challenge in every country, with the emergence of pan-drug resistant bacteria. However, few data are available concerning clinical consequences of in-vitro defined resistances. This wide retrospective study aimed at comparing in-hospital mortality of intensive care infections, according to bacterial resistance profile.

Materials and Methods: Health-care associated infections are monitored in a national prospective registry, managed by the Investigation and Surveillance of Healthcare-Associated Infections Network (RAISIN). Data included in the registries from 2000 to 2013 were analysed. Sub-group analysis was performed using one-way ANOVA.

\begin{tabular}{|l|cc|c|c|} 
Pathogen & $\begin{array}{c}\text { Incidence } \\
(\%)\end{array}$ & $95 \% \mathrm{Cl}$ & $\begin{array}{c}\text { Resistance } \\
(\%)\end{array}$ & $95 \% \mathrm{Cl}$ \\
\hline Staphylococcus aureus & 19.9 & {$[19.0-20.8]$} & 30.7 & {$[28.5-32.9]$} \\
\hline Pseudomonas aeruginosa & 15.7 & {$[14.9-16.5]$} & 43.9 & {$[41.2-46.6]$} \\
\hline Enterobacter spp. & 7.2 & {$[6.6-7.8]$} & 72.6 & {$[69.0-76.2]$} \\
\hline Klebsiella pneumoniae & 3.1 & {$[2.7-3.5]$} & 64.9 & {$[59.1-70.7]$} \\
\hline Enterococcus faecalis & 2.2 & {$[1.9-2.5]$} & 8.6 & {$[4.6-12.6]$} \\
\hline Acinetobacter baumanii & 1.1 & {$[0.9-1.3]$} & 70.5 & {$[61.3-79.7]$} \\
\hline Enterococcus faecium & 0.6 & {$[0.4-0.8]$} & 49.0 & {$[35.0-63.0]$}
\end{tabular}

Results and Discussion:Among the 8793 I patients retrieved, 10001 presented a health-care related infection, including 3092 resistant germs (36.7\% (95\% Cl [35.7-37.7]). Infections were caused by gram negative bacilli in $54.7 \%(95 \% \mathrm{Cl}[53.6$ - 54.8]) of cases and gram positive cocci in $30.0 \%(95 \% \mathrm{Cl}$ [29.0-31.0]) of cases. Gram negative bacilli presented the highest rate of resistance $(52.8 \%$ $95 \% \mathrm{Cl}[51.3-54.3])$, in comparison to Gram positive cocci $(48.1 \%$ $95 \% \mathrm{Cl}[46.3-49.9])$.

In-hospital mortality was higher in case of infection if the germ had antibiotic resistance $(51.9 \% 95 \% \mathrm{Cl}$ [50.I-53.7] vs $45.5 \% 95 \% \mathrm{Cl}$ [44.2-46.8], $\mathrm{p}<.00 \mathrm{I})$ and critical care length of stay was longer ( 33.5 \pm 26.0 vs $29.5 \pm 22.9$ days, $p<.001)$. These results remained significant after SAPS II matching $(\mathrm{P}<.00 \mathrm{I})$, and were identical in the gram negative bacilli and gram positive cocci sub-groups.

Comparing patients according to their origin before admission, no difference of mortality was found. However, more resistant bacteria were found in patients coming from intensive care units $(45.8 \%$ $95 \% \mathrm{Cl}[4 I .5-50 . \mathrm{I}])$ or conventional units $(39.3 \% 95 \% \mathrm{Cl}[37.6-4 \mathrm{I}])$ than from home $(33.5 \% 95 \% \mathrm{Cl}[32.1-34.9])$ or long term care or rehabilitation centres $(33.5 \% 95 \% \mathrm{Cl}$ [28.8-38.2]).

Central venous catheter infections were associated to the highest rate of resistance $((75.0 \% 95 \% \mathrm{Cl}[63.2-86.8])$, in comparison to pneumopathies (48.2\% 95\% Cl[46.6-49.8]), bacteraemia (48.7\% 95\%Cl[45.3-52.I]) and urinary tract infections $(40.8 \% 95 \%[37.5-$ 44.I]).

Conclusion: Bacterial resistance is associated with a higher ICU mortality and increased length of stay, regardless of germ or origin of the patient. 